\title{
O PAPEL DA TUTELA NA CONSTRUÇÃO DE NARRATIVA POR CRIANÇAS
}

Lélia Erbolalo Melo*

RESUMO: A inlenção é mostrar que a lulela de linguagem na siluação de restiluição de narralivas por crianças não aparece como um fenômeno linear; mas anles como uma mistura de gêneros discursivos entremeados de relornos, pedidos de. reformulação, de confirmação...

PALAVRAS-CIIAVE: uulela; linguagem; narraliva; criança.

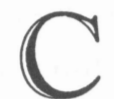

omo ajudar uma criança a falar? () objetivo nesta exposição é apresentar certos aspectos da relação de tutela criança adulto e criança-criança, numa situação de narrativa, após a leitura de uma história. Esta metáfora da tutela, segundo Hausendorf (1993: 96), semete a um conceito segundo o qual o adulto utiliza suas competências superiores para instaurar um nível de interação que a criança não poderia atingir senão por suas próprias capacidades. $\mathrm{O}$ adulto permite, então, à criança participar das interações lingüísticas e pré-lingüísticas. É a este fato $\mathrm{e}$ aos diferentes aspectos do como que remete o termo tutela. Muitos estudos, referentes sobretudo a produções discursivas ligadas a tarefas, mostraram como o que a mãe, ou geralmente o parceiro mais competente, traz à interação favorece $\mathrm{e}$ facilita as atividades da criança.

Ao lado dos estudos empíricos de Bruner e seus colaboradores, é preciso mencionar aqui sobretudo os estudos empíricos marcados pela redescoberta de Vygotsky nos anos 80.

* Universidade de São P’aulo - USP? 
MEL_O, Lélia Erbolato. O papel da lutela na construção de narrativa por crianças.

Inspirando-se no conceito vygotskyano de "zona de desenvolvimento proximal", estes estudos analisam interações adulto-criança em torno da solução comum de um problema ou de uma tarefa que a criança é ainda incapaz de conduzir com êxito sozinha. Elas visam mais particularmente à ajuda que traz o parceiro adulto e tentam relatar a aprendizagem de faculdades bem definidas (por exemplo, reconstituir quebra-cabeça ou construir alguma coisa segundo um modelo) e compreender esta aprendizagem de um ponto de vista microgenético ou em termos de processo.

\section{O CONCEITO DE TUTELA}

Foi desenvolvido por J. S. Bruner e se refere ao campo teórico explorado por L. Vygotsky. Neste sentido, seria interessante resgatar rapidamente a polêmica de Vygotsky em relação a Piaget. Conhecenos a ênfase colocada por Piaget nos estádios e, portanto, numa gênese antes de tudo interna ao sujeito. A apresentação da noção de tutela em Vygotsky faz-se sob forma de uma dupla polêmica: contra a visão de estádios provocando uns c outros partidários de Piaget e contra a idéia de pura e simples transmissão de saberes. Ele nos mostra, então, como o adulto ajuda a criança a fazer com vários o que ela não pode fazer sozinha.

Dito isto, pode-se definir inicialmente a tutela como o conjunto das intervenções (do adulto, mais freqüentemente, mas também de outras crianças) que tem como efeito permitir à criança realizar uma tarefa que cla não conseguiria realizar sem esta ajuda. Em seus propósitos sobre as relações de "tutela" entre os dois parceiros, Bruner mostra o papel fundamental do "expert" que dirige, orienta, estrutura a troca a fim de que se instale o sistema de transmissão dos saberes. Ele designa precisamente por tutela o conjunto das intervenções deste parceiro competente que tem como efeito permitir ao parceiro menos competente realizar uma performance que não teria êxito sem esta ajuda. Como lembra Hudelot, estas intervenções de tutela (ou tuteladas) não se limitam às únicas informações necessárias 
e suficientes que permitem ao aprendiz superar uma nova etapa: são "condutas com múltiplas funções que introduzem a díade ao mesmo tempo nos planos cognitivo, afetivo e relacional". Por outro lado, as análises de Bruner indicam que as condutas de tutela do adulto variam segundo a idade e as necessidades da criança. Pode-se aprimorar esta definição evidenciando certas características da tutela. É o que pretendemos fazer nesta apresentação.

\section{SOBRE AS CONDUTAS DE TUTELA}

Elas não se definem pela intenção subjetiva de tutelar, mas pelos efeitos resultantes: uma mesma intenção com objetivo educativo pode ser eficaz num dado momento, com uma dada criança, e ser totalmente ineficaz, e até constituir um obstáculo à aprendizagem (contra-tutela) com uma outra criança, ou em outro momento.

\section{A TUTELA NĀO É...}

... um apoio estático, uma escora impedindo uma construção de desabar. Ela deve ser compreendida numa perspectiva dinâmica, aquela do desenvolvimento da criança. É uma ajuda fornecida no momento oportuno, que permite à criança conquistar um novo poder, um novo saber, desenvolvendo uma de suas potencialidades.

\section{A TUTELA PELO ADULTO: ALGUNS FIOS CONDUTORES}

Numa primeira aproximação, segundo Hudelot, a tutela de linguagem constitui o conjunto das condutas verbais de um locutor competente sobre e a partir das quais um locutor menos competente elabora seu pró- 
MELO, Lélia Erbolato. () papel da tulela na construção de narrativa por crianças.

prio discurso. Definida menos por sua forma que por seus efeitos, esta tutela pode ser caracterizada em quatro pontos de vista: a) aquele dos tipos de enunciados que o adulto dirige à criança; b) aquele dos modos de encadeamento que ligam o discurso do adulto àquele da criança; c) aquele da localização destes enunciados cm relação à tarefa a efetuar, c d) aqucle dos efeitos do discurso do adulto sobre o modo pelo qual a criança realiza a tarefa.

Em seu trabalho de apoio do discurso infantil, o adulto cumpre papéis que dependem não somente do memorial e do cognitivo, mas igualmente do afetivo e do relacional. Ao mesmo tempo que ele reativa, de modo mais ou menos implícito, a memória da criança, ele ajuda a organizar sua narrativa mantendo com ela uma boa relação interpessoal.

Assim, quanto à tarefa a executar, podemos, então, considerar a tutela como uma antecipação metacognitiva de "dizer", e também como a realização de uma codificação particular da experiência, ou ainda, como a avaliação de uma colocação em palavras ("mise en mots", para Frédéric François). A título de ilustração, citamos um exemplo de "tutela insistente" extraído de François (1996: 140-141). N verdade, este exemplo traduz o estilo imaginário-pedagógico (artificial) contrastado das mães. De fato, há um artifício na medida em que se pede a mães de crianças de $4 \mathrm{c}$ 5 anos para executarem uma tarefa que não lhes é necessariamente "natural", e a de "fazer falar" sua criança, a partir de um desenho representando crianças na cantina. Vejamos apenas um fragmento:

"Mãe: Elas comem... e elas comem cm casa? Elas comem o quê? Elas comem onde?.

Criança Num restaurante. E então... clas são... são quantas em cada mesa? São muitas, em cada mesa? É como em casa? Somos dois ou três à mesa?".

Dito de outro modo, podemos conceber pelo menos três posições que serão numeradas de 0 a 2 . A posição 0 é aquela da expectativa ou da antecipação. Corresponde, no plano dos enunciados, ao lugar das ques- 
tões, das ordens e, geralmente, dos pedidos. Em posição 1, o adulto responde no lugar do sujeito. Ele esboça uma resposta, propõe sua codificação. Enfim, a posição 2 é aquela tradicionalmente atribuída à continuação (Hudelot, 1994: 204-205).

Em compensação, podemos interrogar sobre o trabalho de assistência do adulto e de sua eficácia. Se não olhamos apenas para os tipos de enunciados emitidos pelo adulto, mas nos interessamos igualmente pelos conteúdos que eles veiculam, percebemos que o adulto conduz conjuntamente vários tipos de atividades. No que diz respeito à tarefa que a criança está cumprindo, podemos dizer que a tutela é global ou local, direta ou indireta, e que a referência ao gênero narrativa é tácita, implícita ou explícita.

Por outro lado, consideramos, retomando uma distinção estabelecida por Bateson, que a tutela se situa ao mesmo tempo na esfera dos conteúdos (a história, com scus participantes, suas ações e suas motivações) e naquela da relação que mantêm os interlocutores (os papéis que assumem, num sentido sócio-afetivo, os modos de relação que instauram com o outro).

Prosseguindo um pouco, c ainda nesta mesma linha de reflexão, observamos que muitas intervenções fornecem à criança uma espécie de esboço, de molde discursivo categorial para que cla possa atualizar sob forma de conteúdos particulares não necessariamente semelhantes àqueles da narrativa original. Neste sentido, recorro mais uma vez ao texto de Hudelot (1994: 206) com o objetivo de exemplificar o que acabou de ser colocado.

O cxemplo $\mathrm{cm}$ questão trata de uma interação entre Sandrine c Olivier, e que acaba se transformando quase num exemplo caricatural: atualizam-se inicialmente os participantes, depois os acontecimentos.

S. - "Então, Olivier, o que você entendeu desta história?

O.- (silêncio).

S. - Então, cla fala de quê? Ela fala de quê esta história? 
MELO, Lélia Erbolato. O papel da tutela na construção de narrativa por crianças.

O. - De sapatos.

S. - Sim, de sapatos. E então? Quem está nesta história?

O. - Um menino.

S. - Hum, hum, e depois?

O. - (silêncio).

S. - O que acontece com este menino?

O. - Ele quer os sapatos

S. - Sim, ele quer os sapatos. E daí, o que acontece?

O. - (silêncio)."

Verificamos neste exemplo que o adulto pode fazer referência ao gênero discursivo "narrativa" de modo direto, falando explicitamente de história, quando ele convida a criança, através de um enunciado dirigido, a restituir a narrativa. Mas esta referência ao gênero narrativo pode também ser feita implicitamente, quando o adulto introduz (ou reintroduz) a noção de acontecimento:

"O que acontece, o que acontece.";

ou de cronolosivi:

S. a C. - "E depois, o que aconteceu";

ou remete ao fato que, regra geral, uma narrativa apresenta um fim:

S. a C. - "Como termina eșta história".

Outra característica, relativamente específica a este tipo de diálogo, é a reformulação recapitulativa (freqüente, é verdade, no discurso didático...). Em geral, cla é marcada pelos conectores então ou daí.

S. a C. - "Então você me disse que... 
Daí os homens ajudaram a fabricar os...

Então, no início, ele é pobre..."

Um outro modo de introduzir este resumo recapitulativo é apresentar explicitamente o discurso como reportado.

S. a C. - "Você dissc que o sapateiro fabrica sapatos, cle...

S. a C. - Daí você me disse que cra a história de um sapateiro que...

I. a C. - Então é preciso lembrar um pouquinho: é a história..."

É a história de quem?

Esta recapitulação pode mesmo ser explicitamente apresentada como melhor formulação:

I. a J. - "Então, se eu entendi bem, havia um homem que era pobre e se tornou rico, hein?

Encontram-sc igualmente o que se pode chamar "avaliações". Esta categoria leva cm conta o que vai da atenuação:

I. a J. - "Se você não sabe a palavra, você pode me explicar, não faz mal sc você não sabe a palavra.

- Você não se lembra. Bem, não faz mal"

\section{À GRATIFICAÇĀO:}

I. a J. - "Está bem. É tudo? Muito bem.

S. a C. - Mas muito bem, diga então.

S. a C. - Sim, muito bem",

passando por encorajamentos (freqüente em Olivier) sob 
MELO, Lélia Erbołato. O papel da tutela na construção de narrativa por crianças.

forma de ordem:

S. a O. - "Você me disse"

ou de direcionamentos indiretos:

Então você pode me dizer como termina esta história?"

Concluindo: em todos os casos citados, trata-se de um controle da frustração, de um lado, que permite à criança ter êxito na tarefa que the é solicitada c, de outro lado, de uma manifestação c confiança para que ela tente se lançar, com menor possibilidade de riscos, numa atividade para a qual falta ainda segurança ou autonomia. (Iudelot, 1994: 209).

Finalmente, c ainda na seqüência de exemplos, a "tutela como movimento": no diálogo a seguir (adaptado ao português), como cm outros, segundo Hudelot (1994: 211-212), a linearidade da narrativa é, às vezes, rompida por seqüências laterais iniciadas por pedidos de confirmação ou de explicitação com base geralmente na identidade dos participantes. $O$ que nos surprèende é o fato que o adulto solicita à criança para reformular o que ela já cnunciou anteriormente. Assim, nesta seqüiência entre Sandrine e Wassila. Esta última acaba de fazer uma restituição digna de citação:

S. - Este homem está sozinho?

W. - Não, cle está com sua mulher.

S. - Sim, ele está com sua mulher. Muito bem. E como sc chamam estes homenzinhos? Você se lembra? (silêncio de W.). São elfos, como duendes. E o homem na história, o que ele faz?

W. - Eu não me lembro mais.

S. - Ele conserta sapatos, você me disse.

W. - Ah, sim, cle fabrica sapatos.

S. - Como... 


$$
\begin{aligned}
& \text { W. - Eu não sci } \\
& \text { S. - um sa... } \\
& \text { W. - . .ppateiro }
\end{aligned}
$$

Com base nas colocações feitas, vemos que a tutela não aparece como um fenômeno linear, mas antes como um dos aspectos mais importantes quando se trata do desenvolvimento das competências discursivas em crianças.

RÉSUMÉ: L'intention est de montrer que l'élayage de langage dans la situation de restitution de récils par des enfants n'apparaîl pas comme un phénomène linéaire, mais plutôt comme un mélange de genres discursifs entremêlés de retours en arrière, de demande de reformulation, et de demande de confirmation.

MOTS-CLÉS: élayage; langage; récil; enfant.

\section{BIBLIOGRAFIA}

BRUNER, J. S. (1991). Le développement de l'enfant. Savoir laire, savoir dire. Trad do inglês de Michel Deleau. $3^{\mathrm{a}}$ ed. Paris, P.U.F. Cap. 10.

FRANÇOIS, F. (1996). Prálicas do oral: teorias e prálicas. Diálogo, jogo e variações das figuras do sentido. Trad. de I célia Erbolato Melo. São Paulo, Pró-Fono. Cạ). 4.

HAUSENDORF, H. "L'adulte auditeur: aspects de l'étayage dans l'interaction avec des narrateur's enfants". In: Al/ E, n"2 -b-, 1993.

IIUDELOT, C. (1994). Modalités de l'étayage langagier dans la restitution de récits de dix enfants présentant des difficultés de langage. In: BRES, J. Questions de narrativité. Montpellier III: 203-213.

VYCOTSKY, L. S. (1987). Pensamenlo e linguagem. Trad. de Jeferson Luiz Camargo. São Paulo, Martins Fontes. Cap. 2.

(1991). A formação social da mente. Trad. de José Cipolla Neto et alii. $4^{\text {a }}$ ed. São Paulo, Martins Fontes. Cap. 6. 